\title{
ETHNIC LINKS, LOCATION CHOICE AND PERFORMANCE: A TEST OF THE RURAL MOTEL INDUSTRY
}

\author{
Arturs Kalnins \\ Marshall School of Business \\ University of Southern California \\ Wilbur Chung \\ Stern School of Business \\ New York University
}

October 2000

\begin{abstract}
:
This paper explores whether membership in ethnically based groups influences conduct and performance in a spatially dispersed industry. We test two propositions. First, when group members own several units in a given market, prices and revenues might be similar to when just one person owned these units. Second, if group membership provides such performance benefits, members may locate their units to obtain these benefits. Using over a thousand hotels located in rural Texas, we test the role of ethnic group membership by examining hotels owned by individuals with the surname "Patel". This surname is common in the hotel industry, with some estimates of Patels owning one in four US motels. Though most are not directly related, much anecdotal evidence suggests that Patels try to lessen the competition among their units. Interestingly, we find that for Patel owned hotels, proximity of other Patels confers no performance gains. While collocating at a regional level, Patels do not collocate at the finer zip code level, which prevents them from coordinating to enhance performance.
\end{abstract}

COMMENTS WELCOME. We acknowledge the helpful comments of Joel Baum, Avijit Ghosh, and Henrich Greve on prior drafts. Errors remain our own. Correspondence to kalnins@usc.edu or Bridge Hall 307H, Marshall School of Business, University of Southern California, Los Angeles, CA 90089-1421. Phone: (213) 740-9683. Fax: (213) 740-3582. 


\section{ETHNIC LINKS, LOCATION CHOICE AND PERFORMANCE: A TEST OF THE RURAL MOTEL INDUSTRY}

\section{Introduction}

Firms that own multiple units within a market or that repeatedly contact other firms across multiple markets may coordinate prices in such a way as to enjoy performance higher than if the firms were active competitors. Typically, such coordination requires the multiple units to be owned by the same firm. Yet, recent research suggests that informal relationships can also sometimes influence firms' performance. For example, Ingram and Roberts (2000) show that luxury hotels in Sydney Australia experience greater revenues per room when their top managers are friends when they admire each other and have repeated informal exchanges. Beyond formal links via common ownership, Ingram and Roberts demonstrate that informal relationships provide the basis for firms to achieve performance differences.

We extend this inquiry of the importance of informal relationships within an ethnic business network. Past studies on networks of expatriate Chinese entrepreneurs have concluded that trust (Wong, 1988) and organization flexibility resulting from network membership (Redding, 1996) have yielded superior performance outcomes for network members. In this study, we examine whether informal links via ethnic group membership among multiple collocated firms cause conduct and performance outcomes similar to those of a single firm that enjoys market power. Group membership and informal relationships provide channels for members to coordinate their actions and mechanisms to discipline members who deviate from the coordinated activity. Group membership provides informal governance - the more important the group membership, the stronger the governance. Two propositions emerge. First, when several firms in a given market are owned by group members, we expect pricing and performance to be similar to a market where all those firms are owned by the same owner. Second, if group membership confers performance benefits, we expect members of the group to locate their firms in configurations to obtain and increase these benefits.

Our empirical setting is the rural Texas hotel industry for the period 1991 through 1998. In this context, we study one specific ethnically based group: hotel owners with the 
surname "Patel". We focus on Patels since they currently play an important role in this industry - as a group they own a significant percent of non-luxury hotels in the US. Asian Indian Americans own over 30\% of the American hotel-motel business, according to Mike Patel, chairman of the Asian American Hotel Owners Association. ${ }^{1}$ And among Asian Indian America hoteliers, "Patel" is the most common surname. A main reason why the Patels have come to play a key role in the hotel industry is their sheer numbers; the name is very common in the Gujarat state of India where most Asian American hotel owners emigrate from, more so than Smith or Jones in the United States.

Given the name's commonness, the likelihood that two Patels in disparate locations are directly related is low. Consistent with this, sources often include quotes like: "It gets so confusing," states Pushpa Patel, owner of a Howard Johnson's in Paramus, NJ. "Guests are constantly saying to me, 'We stayed at a hotel and the manager was so-and-so Patel. Is he your cousin or your brother?"' 2 While not originating from the same nuclear family across states, anecdotal evidence suggests that Patels typically collaborate with each other in the management of their hotels. Other anecdotes suggest that those Patels in close proximity often are direct relations, which would enhance informal governance beyond just ethnic group membership.

Overall, while expecting Patel owned units to experience enhanced financial performance when surrounded by other units also owned by Patels and therefore for Patels to collocate; we find that proximity of other Patels confers no performance benefit. Further investigating the lack of performance we find that while Patels locate regionally proximate to one another, they do not locate in close proximity; they locate in the same regions, but not the same zip codes. Likely the lack of close proximity permits non-Patel owned hotels to locate intermediately, which reduces the Patels' ability to coordinate among themselves and thus achieve enhanced financial performance.

The structure of the paper is as follows. First, we present information about the phenomenon of Patel-owned hotels, both from other sources and from our data set. We describe the nature of the ties within the community of Patels, as well as some explanations for the evolution of the dominance of Patels in the hotel industry. Second,

\footnotetext{
1 “Indians Find Niche in Hotel Industy,” New Orleans Times-Picayne, September 24, 1998, p. 4A1.

${ }^{2}$ Ibid, p. B1.
} 
we present simple hypotheses regarding the pricing decisions and revenue performance of the Patel hotels. Third, we present hypotheses regarding the location of the Patels and present results of a full-information nested logit model. The fourth section concludes.

\section{Patel Hotels}

Patels are Asian Indian Americans, coming mostly from the western coastal state of Gujarat in India. They represent a surprisingly high percent of owners among nonluxury hotels and motels in the United States. The Asian American Hotel Owners Association reports that "nearly all of the trade group's 4,000 members are named Patel." Consistent with pervasiveness of Patel owned hotels, our data for the rural Texas hotel industry shows that 59 of 741 hotels (8.0\%) first opened after 1990, were opened as sole proprietorships by Patels or by corporations where one owner is a Patel. We define as rural the units that lie outside the six largest counties in Texas, those that contain Dallas, Fort Worth, Houston, San Antonio, Austin, and El Paso. At the end of 1998, 310 of 2057 rural Texas hotels/motels (15.1\%) with 15 rooms or more were operated as sole proprietorships by Patels or by corporations where at least one owner is a Patel.

India Abroad, a publication for Indian expatriates, believes the first Patel to go into the hotel business was Nagiihhai Patel, who bought his first motel in Sacramento in 1933. ${ }^{4}$ From there, Millman (1997) chronicles the rise of the Patel owned hotels. When India was a British colony, Patels wound up in England or in African colonies such as Malawi, Zambia and Uganda. Many Patels were expelled from Uganda during the brutal reign of dictator Idi Amin in the 1970s, who also confiscated their businesses. Fleeing with limited savings, these Indian expatriates searched for suitable destinations.

These Indian expatriates and subsequent Indian immigrants found non-luxury hotels in the US an attractive business opportunity for several reasons. First, entry barriers are low. With an investment of $\$ 40,000$, the displaced could secure immigrant status in the United States. The question became "What to invest in?" With a $\$ 40,000$ investment, choice was limited to small establishments such as diners or roadside motels. Versus other choices, rural hotels provide both a business opportunity and a place of residence. Brothers C.Z. and D.Z. Patel own the Villa Inn, a 1960s-vintage 40-room

\footnotetext{
3 "What's in a Surname? A passel of Patels: Indian Moniker is Big in Motel Biz," The Record - Northern New Jersey, August 10, 1995, p. B1.
} 
motel. "It's like a home business," said D.Z. Patel, 45, who was a mechanical engineer in India before he came to the United States 10 years ago. "You live on the premises and save money." D.Z. Patel moved to Colorado City with his wife and two children in 1997. They live at the Villa Inn with his brother's family. The only non-family member who works at the motel is a part-time housekeeper. ${ }^{5}$ Choosing to operate a hotel provides Asian Indian immigrants both a livelihood and lodging. Finally, their East Indian cultural background limits their choices. Operating restaurants was not palatable since as Hindus, they were uncomfortable handling meat. And being foreigners, they found difficult the face-to-face interactions restaurant work requires, such as seating the customer, taking the order, serving, revisiting the customer, bringing a check and bringing change. Therefore, the Patels developed the Indian motel plan, renting rooms for $\$ 25$ to $\$ 50$ a night, with minimal customer interaction. The plan was once half-jokingly described as: "Here is your room. Here is your key. Goodbye."

Contagion further increased the size of the Patel hotel community. Much like the format adoption of radio stations described in Greve (1995), the Patels' likelihood of choosing to operate a hotel in the low-price market niche was higher than other potential owners due to contagion, in this case based on their ethnic background. Millman reports that the well-maintained but no-frills "Patel motel" not only created a new market, but was so successful that it forced full-service hotel chains such as Marriott to respond with "economy" lodgings.

Not initially having the resources to afford more expensive hotels, Patel-owned hotels often lie in rural areas and along highways. For example in Texas, Pankaj Patel, Mahesh Patel, Hasmukh Patel and Pravin Patel own motels in the Midland-Odessa area. At least four Patels own motels in Lubbock. Both of these towns are over 300 miles from any large Texan city. Other articles in the popular press confirm similar trends across the United States.

Once in the US, initial immigrants attracted a profusion of followers through family and friendship ties, enabling the contagion to take place. One sibling would help find a suitable hotel for their siblings and other relations. One article from Oregon

\footnotetext{
${ }^{4}$ India abroad, Summer, 1989.
} 
describes how one family's location choice planted the seed for an entire community. Nick Patel, the article states, and several dozen other Patels have carved a niche in the metro Portland area's economy lodging industry. ${ }^{6}$ The article discusses how Nick's move to Portland in 1978 made the area more attractive for other Hindu immigrants. Nick became a leader of the local Hindu community, almost all of whom are innkeepers. These familial ties increase the likelihood of a new arrival's success by providing managerial knowledge, emotional support, and financial assistance.

However, such assistance was not limited to just nuclear families. "Whenever one of our countrymen runs into trouble, we are always there to help him out," says Deepak Bhayani, a 49-year-old Indian-born franchisee with Dunkin' Donuts shops in two Illinois. When Mr. Bhayani was unable to work for two months because of heart-bypass surgery, he says other immigrant franchisees stepped in to supervise his stores - including Amrit Patel. "They are my friends," Mr. Patel says. "When friends need help, I always go for it." ${ }^{, 7}$ Such behavior is consistent with Granovetter's (1995) argument that informal links can provide advantage when entities are simultaneously "coupled" and "decoupled". Entities upon whom reciprocal claims can be made are coupled to each other, but being coupled to many others can be detrimental - too many potential claims can lead to claims going unanswered. Immigrant business owners as minorities are coupled to each other through their ethnicity but are also simultaneously decoupled ethnically from the majority (they are also geographically decoupled from others of their same ethnicity in their home country).

"In India, everybody thinks like a family," Bob Patel, owner of a Red Carpet Inn in North Carolina, said. "We try to help each other." People from India looking to own a business might logically choose the lodging industry, he said, because so many of their friends own hotels and motels. Established innkeepers can advise and support newcomers. Further, these immigrant communities maintain close and regular contact. For example, fifty Hindu families meet weekly for religious observances in the Portland area. Bob Patel states further "The Indian immigrants will share information with each

\footnotetext{
${ }^{5}$ All quotes from this paragraph taken from "Where the East meets West. Texas Indian immigrants' 'Patel motels' thrive," The Dallas Morning News, April 25, 1999

${ }^{6}$ All quotes in this paragraph taken from "Immigrants Find Sweet Success in Lodgings," Portland Oregonian, April 22, 1999.
} 
other about which banks offer the lowest rates on mortgages. They'll spread among themselves the names of customers who have stiffed them on a room bill. To save money, they'll join forces to buy televisions and other motel equipment in bulk. When times are tight, they'll loan each other money."

The proliferation of hotels owned by East Indians might heighten competition among them, especially if they are proximately located. The location of Patels proximately to one another is a likely outcome since existing immigrant hoteliers often assist subsequent entrants by identifying suitable properties. Such a search for suitable properties is likely bounded by distance - an existing hotelier can ill afford to travel far from their own hotel. This heightened competition might outweigh the benefits that accrue through family and ethnic ties. Aldrich and Waldinger (1990) argue that while offering benefits, ethnic groups are also their own most likely competition. For example, when asked why he was forced to go back to accepting business from prostitutes, Dallas motel-owner Chandrakant Patel said, “After awhile, you say, 'I can't survive, I've got to go back to hourly rates.' Competition among the various Patels is the biggest problem we have."

While some note the heightened competition, surprisingly, many Indian hoteliers say they don't mind the added competition. The benefits of numbers apparently outweigh the costs. Suresh Gupta, an Indian hotelier who owns a Holiday Inn near Orlando, states that he would help any Indian asking for advice on a hotel location. Gupta claims he would even loan such a person the money to start, even if that person would end up a competitor. ${ }^{9}$ The Indian hotel and motel owners are banding together to achieve monopsony power when buying supplies or insurance, which may outweigh the problems of competition. "If you're one person, who cares... they'll drop you like that," said Tulsi Dhanani, who has been in the lodging business since 1983. "But if you have a crowd of ten, you have power. When you're a group, you have strength."10

\footnotetext{
${ }^{7}$ Quotes taken from "Spreading the Dough Around," The Wall Street Journal, February 22, 1999.

8 “Indian Entrepreneurs: Immigrant Patels cashing in on Dallas' sexually oriented motels," The Dallas Morning News, June 14, 1987.

9 "Hands Across the Water: Close-knit Indian Community Strong Force in Economy Hotels," Orlando Business Journal, June 12, 1998, p. 23.

10 "Passage From India Immigrants Work Together To Make A Mark In N.O. Area," The New Orleans Times-Picayune, July 28, 1992.
} 
The initial displacement of Indian expatriates combined with the presence of managerial knowledge, emotional support, and financial assistance accruing through ethnic ties helps explains how the Patel hotel phenomenon grew to its present proportions. Further, the ethnic ties mean that Patel hoteliers need to choose locations trading off heightened competition versus managerial, emotional, and financial assistance. Both result from proximity. Baum and Haveman (1997) emphasize such trade-offs of losses and gains from proximity, which provides many dilemmas for hotel owners in general. They find that new hotels establish themselves at similar prices but of different sizes to those around them in order to reduce the competition but gain from lucrative locations. The Patels have an even more complex set of issues due to proximity than most due to their ethnic ties.

Given the prominence of such a social, ethnic group in the rural hotel industry, we develop propositions as to how group membership affects financial performance and location choice.

\section{Pricing Conduct and Revenue Performance}

\subsection{Theory and Hypotheses}

Given the prevalence of Patels in Texas and the ethnic links influencing their location patterns, proximity among Patel owned units is inevitable. We ask how this proximity affects the performance of Patel operated hotels.

Industrial economists such as Levy and Reitzes (1992) and Werden and Froeb (1994) have studied the effects on price of mergers in a spatial setting. Their theoretical work shows that ownership of multiple nearby outlets allows an owner to charge higher prices relative to what would be charged with the same configuration of outlets under separate ownership due to the spatial market power they enjoy. Consistent with such hypotheses, Conlin (1999) presents evidence that hotel room prices are higher when the same owners own multiple units in a city. Even if spatially dispersed outlets are owned by different owners, they may collude on price under certain conditions, yielding price and performance outcomes similar to those of the spatial market power case. In the standard game theoretic arguments (e.g., Fudenberg and Tirole, 1991) and specifically in a geographic multimarket context (Bernheim and Whinston, 1990), firms can maintain a 
collusive agreement if each firm can construct a punishment for the other that outweighs the benefit of reneging on the agreement.

Williamson $(1993,1996)$ emphasizes the role of such calculative behavior in the trust that allows firms to maintain collusive agreements. While the punishments available to firms are typically restricted to lowering price in future periods, economists have pointed out that loss of reputation within a group can also serve as a type of punishment that would prevent an individual from reneging on an agreement (e.g., Ellickson, 1989). Sociologists have argued that the mechanism through which agreements are more likely to be respected when a party is part of a group may not be a calculated response to a threat of punishment. Uzzi (1996) discusses a heuristic character of trust that appears inconsistent with rational calculation, yet facilitates the exchange of assets that benefit both parties. Regardless of which of these approaches is preferable to the reader, both suggest that members of a group are more likely to cooperate than those who share no group membership.

In our empirical context, Patels who belong to the same social and ethnic group may have such punishments available - they may not be allowed to participate when other Patels group purchase from suppliers or they might be made to feel unwelcome at community gatherings. Given such potential penalties, we expect Patels who operated hotels that are proximate to each other will be able to coordinate their pricing policies. Assuming the Patels jointly optimize prices along with occupancy, then they would also experience increased revenues. More formally, we propose:

Hypothesis 1: If agglomeration by Patels is likely due to maintenance of pricing agreements, Patels should be able to charge higher prices than their equivalent non-Patel competition.

Hypothesis 2: If agglomeration by Patels is likely due to maintenance of pricing agreements, Patels should enjoy higher revenues than their equivalent non-Patel competition.

\subsection{Data}

Our data were provided to us by the Texas State government and includes all establishments operating as hotels or motels in Texas for the quarters between the years of 1991 and 1998 inclusive. The data provides a hotel's name, opening date, street 
address, owner name, owner location, size in rooms, and revenues. In the original data, often hotel owners are listed as corporations and Patels might own some of these corporations. Therefore, to identify Patel-owned corporations, we used the Texas State incorporation-listing file and compared the list of all corporations owned by Patels with the corporations that owned hotels. Any hotel that has an owner with or that is incorporated and has a partner with the surname "Patel" we identify as a Patel owned hotel.

While primarily hotels and motels, this data also includes many bed and breakfasts, rental rooms in private residences, and time-share condos. We purposefully want to exclude such occurrences, which do not operate in the same segment as hotels and motels; bed \& breakfasts are often destinations themselves, while hotels and motels are temporary housing on the way to or proximate to travelers' end destinations. To remove such observations, we examine an establishment's reported number of rooms and remove the observation if the number of rooms is below fifteen. After applying the greater than fifteen rooms cutoff, on average 1,600 establishments remain in each quarter of data.

We use zip codes to define market locations, which is the finest level of geographic gradation available in our data. In rural Texas, typically a zip code only contains one if any freeway exits. Since the likelihood of a hotel being in a zip code but not at a freeway exit is small, we say hotels are agglomerated when they are in the same zip code. Therefore, any hotels in the same zip code, we assume to be agglomerated - or collocated around the freeway exit.

From the original Texas government data, we obtain one dependent variable: revenues per room, which is an industry standard measure of performance. Revenues can increase through greater occupancy, higher prices, or a combination of both. All these possibilities increase revenues. Instead of just total revenues, we scale a hotel's revenues by its number of rooms since we are interested in an establishment's performance relative to its size. Large hotels are clearly going to have higher revenues than smaller hotels; we ask if a hotel performs better than other hotels, given its size.

To obtain our second dependent variable, room prices, we conducted a phone survey. Between May 15 and May 20, 1999, we conducted a price survey of all rural 
hotels with current telephone listings in the Yellow Pages. We were able to contact 1097 active telephone listings and asked these hotels for their price including tax for one room for one person on weekdays and weekends. ${ }^{11}$ The results presented below are based on the weekday prices, which in most cases, do not vary from the weekend prices. Of these 1097 hotels, Patels owned 171.

Given our price data is only for early 1999, we use revenue per room data from the Texas government for the closest comparable period available, the $4^{\text {th }}$ quarter of 1998. To explain differences in revenue per room and prices, our variables of theoretical interest are: (1) a dummy variable indicating whether a given hotel is owned by a Patel, (2) the percentage of hotel rooms in a zip code owned by Patels, not counting the current hotel, and (3) an interaction term of these two variables. ${ }^{12}$

Other variables are included as controls. These include hotel-specific measures such as size in rooms of the hotel, an incorporation dummy, the number of stars that AAA has assigned to the hotel, and multimarket contact at an owner and chain level. The multimarket measures are the typical count measures of total markets of overlap (Evans and Kessides, 1994; Gimeno, 1999); as mentioned above, we define a market at the zip code level. The other variables are zip code level controls including population, average income, aggregate number of hotel rooms, whether an interstate runs through the zip code, and a Herfindahl index of concentration. This index can be written as $\sum_{\mathrm{k}}(\text { share })^{2}$ where share the percentage of rooms in zip code owned by owner $\mathrm{k}$. This variable ranges from zero to one, with zero indicating the case of perfect competition and one indicating a monopoly. These measures are constructed from the Texas State data or obtained from the 1990 US Census of Population.

\subsection{Method and Results}

We test the financial performance hypotheses using a two-dimensional fixedeffects ordinary least squares model, with price and revenues per room as the dependent variables. Fixed effects are included for each chain and each county. Prices and revenues certainly vary by chain and by location. Holiday Inns will on average earn more than Red

\footnotetext{
${ }^{11}$ Use of prices in the AAA guides was not useful because under $20 \%$ of hotels in our sample were listed in AAA.

${ }^{12}$ All tests were also conducted changing the percentage of hotel rooms in a zip code owned by Patels to a case including the current hotel. None of the results changed in any way.
} 
Roof Inns. Similarly, some hotels might be located in counties home to important rural attractions like the state fairgrounds. To prevent such variation from being attributed to our variables of interest, we include the fixed effects. Thus, the coefficients of all our other variables reflect within-chain and within-county variation. Independent hotels are lumped together as the base case. Note a hotel might both be chain affiliated and operated by a Patel; in such a case both the particular chain dummy variable and the Patel dummy variable would be coded as " 1 ". ${ }^{13}$

The price and revenue per room regressions both contain the same sets of independent variables. The interaction term between (1) the dummy variable indicating whether a given hotel is owned by a Patel and (2) the percentage of hotel rooms in a zip code owned by Patels should have a positive effect on prices and revenues if Hypotheses 1 and 2 are corroborated. The interaction term indicates that a given Patel can charge higher prices because a high percentage of other rooms are owned by Patels, giving them the ability to collude on price.

\section{[ Table 1 about here ]}

As Table 1 shows, all the Patel-related variables are all not significantly different from zero. Both the main effects and the interaction between the main effects are insignificant. Patels do not charge higher prices than anyone does in high-Patel areas, nor do they enjoy higher revenues per room.

While the variables of theoretical interest are non-significant, several controls are significantly different from zero. The controls for hotel traits are signed as expected. Owner level multimarket contact is significantly positive, which suggests that multi-unit owners who encounter each other repeatedly across markets can price higher and thus enjoy higher revenues. Whether a hotel is incorporated significantly increase both measures of financial performance, which likely indicates the relative quality of the hotel - owners of higher quality hotels incorporate. Larger hotels (as measured by room size) charge more; larger hotels have more features that allow them to price higher. And higher

\footnotetext{
${ }^{13}$ Chains in the hotel industry are often franchised. As a result, they are often made up of many small local owners such as the Patels. See Chung and Kalnins (2000) for more details of ownership structures within chains.
} 
quality hotels, as indicated by AAA star ratings, also charge more and earn higher revenues per room.

Most control variables for market conditions within the zip code are also signed as expected. While population and average income are related, together they suggest that hotels set higher prices in wealthier zip codes. Surprisingly, the presence of an interstate in the zip code has negative effects, likely resulting from higher competition in these areas. Presence of an interstate in a zip code needs to be considered together with hotels in a zip code since an interstate will increase demand by providing a conduit for travelers, but such a conduit will then attract more competitors. ${ }^{14}$ The significance of the Herfindahl index indicates that owners raise price when they own more units, confirming the results of Conlin (1999). We note however, that the high concentration as measured by the Herfindahl has no revenue performance benefit.

Given that most control variables conform to expectations, the lack of effect for the three Patel variables is curious. Given that we expect Patels to informally coordinate over prices, such coordination requires physical proximity. Therefore, to better understand the non-significant results, we investigate further and examine location choice.

\section{The choice of location of new hotels \\ 4.1 Theory and Hypotheses}

As a starting point, we ask "are Patels likely to agglomerate in their location choices in particular areas?" All anecdotes suggest that they will. However, an interesting subsequent question is "what is the reason for the agglomeration?" Is agglomeration merely to be close to other Patels for social and religious purposes? Or is it to be close enough so that information is meaningful and can be effectively exchanged? Finally, is it to be close enough to coordinate pricing decisions for market power purposes? Not surprisingly since such behavior is illegal, none of the Patels quoted in the popular press

\footnotetext{
${ }^{14}$ While initially expecting a negative sign for hotels in zip code and a positive sign for interstate in zip code, the positive sign for hotels in zip code suggests heighten demand results when hotels agglomerate. When multiple hotels are present in one location, this offers travelers greater breadth and depth of selection; this increased selection would increase visitation by travelers, which increases demand and thus the price that hotels could charge. The coefficient estimates suggest that this potential agglomeration gain though heightened demand occurs in zip codes where interstates pass through that have more than 8.4 hotels $(8.4 * 0.854>-7.193)$.
} 
mention pricing agreements as a way in which the Patels could help each other. While not mentioned, such behavior is possible. These questions suggest that we examine location behavior to see how closely Patels physically locate to each other.

If maintaining market power is the primary reason for agglomerating, this would require closer proximity because the hotels would have to be seen as close substitutes by potential customers. While the Patels might locate their hotels further apart to reduce supply and thus maintain market power; the low barriers to entry in the hotel industry likely preclude this possibility - a non-Patel owned hotel might choose an intermediate location that would reduce the Patel's likelihood of coordinating on price. More likely is the possibility that Patels encourage other Patels to locate nearby in order to pre-empt competition, that is, to make the location less appealing for potential non-Patel competition. $^{15}$

On the other hand, if proximity for community and religious activities, or for coordinating purchases, is the primary reason for any agglomeration among Patels, as close proximity as for pricing coordination purposes is not needed. As long as the choice of a particular location allowed the Patels to meet on weekends for religious observances, for example, it would be acceptable. Thus, Patels could build hotels reasonably far apart, even upwards of a hundred miles apart.

Thus, intent should be consistent with the level of agglomeration; agglomeration at a broad level is consistent with social activities, while agglomeration at a fine level is consistent with economic activities. Or stated more formally:

Hypothesis 3: If agglomeration by Patels is likely due to maintenance of pricing agreements or for pre-emption purposes, Patels are likely to agglomerate at a narrow market level.

Hypothesis 4: If agglomeration by Patels is likely due to maintenance of social and religious ties, Patels are likely to agglomerate at a broad regional level.

\footnotetext{
${ }^{15}$ For the basic pre-emption argument, please see Dixit (1980). For the case of pre-emption via multiple locations in geographic or product space, please see Judd (1985) and Hadfield (1991).
} 


\subsection{The Nested Logit Method}

To test these two hypotheses, we model the choice of location for new hotels using the random utility framework. In this model, we treat zip codes in Texas that contain hotels as the elemental alternatives for each choice of hotel location. In the random utility framework, all actors making the choice are assumed to value fundamental attributes of an alternative (such as number of existing hotels in a zip code) equally. We expect to observe different choices of location for two reasons. First, the levels of the attributes for the same alternative are not identical across different actors. For example, as the different actors make their choice at different times, the number of existing hotels in a zip code will change. Second, an error term is also included for each choice for each actor, leading to some variation even if all values of the observable attributes are equal across all actors.

Some of the primary alternatives (the zip codes) in our choice set are likely to share unobserved characteristics due to geographical proximity. Therefore, the error terms of such zip codes are likely to be correlated, and we estimate a nested conditional logit model. McFadden (1978) proves that the nested logit model is consistent with the random utility model of choice preference. Use of nested logit models requires the researcher to choose a nesting structure for the random utility model, that is, to make assumptions regarding the correlation between alternatives. In our case, all zip codes that are within driving distance of a location where the Indian community may hold social or religious events would exhibit a positive unobservable correlation in their probability of being chosen as a hotel site by a Patel. Thus, we split Texas into 25 regions in the first level of our nesting structure. The second level choice set consists of three zip codes per region: the zip code actually chosen and two others that are drawn randomly. ${ }^{16}$ For the regional and zip code levels, we introduce sets of independent variables. Choice among the zip codes tests Hypothesis 3 by assessing the significance of $X_{\mathrm{ij}}$, the zip code level variables. Choice among these regions tests Hypothesis 4 by assessing the significance of $\mathrm{Z}_{\mathrm{i}}$, the regional level variables. This nested logit technique with multiple levels and

\footnotetext{
${ }^{16}$ The selection of 25 regions and 3 zip codes within a region is driven by software constraints. The Limdep 7.0 software package limits the user to 75 elemental alternatives.
} 
choice sampling is a standard technique used commonly among transportation alternative and brand selection studies in economics and marketing.

In our random utility model, we define an underlying latent variable $\mathrm{V}_{\mathrm{ijk}}$ to represent the utility to each new hotel owner $\mathrm{k}$ of opening a hotel in zip code $\mathrm{j}$ within Region $\mathrm{i}$. $\mathrm{i}=1$ to 25 are the 25 regions, each containing $\mathrm{N}_{\mathrm{i}}$ zip codes. $\mathrm{j}=1$ to $\mathrm{N}_{\mathrm{i}}$ are the zip codes within each region $i$ that contain at least one hotel. Then the observed variable $\mathrm{Y}_{\mathrm{ijk}}$ is such that:

$$
\begin{aligned}
& Y_{i j k}= 1 \text { if } V_{i j k}>V_{m n k} \text { for } m=1 \text { to } 25 \text { and } n=1 \text { to } N_{m} \text {, but } n \text { is not equal to } j \text {, and } \\
& Y_{i j k}=0 \text { otherwise. }
\end{aligned}
$$

In other words, we observe the owner $\mathrm{k}$ locating a hotel in zip code $\mathrm{j}$ within region $\mathrm{i}$ if the utility of such a choice exceeds all other choices.

The utility for each owner $V_{\mathrm{ijk}}$ is given by observable characteristics $\mathbf{Z}_{\mathrm{ik}}$ and $\mathbf{X}_{\mathrm{ijk}}$. Assuming a linear relationship between observables and the latent variable, we can write:

$\mathrm{V}_{\mathrm{ijk}}=\mathbf{b}_{1}{ }^{\prime} \mathbf{Z}_{\mathrm{ik}}+\mathbf{b}_{2}{ }^{\prime} \mathbf{X}_{\mathrm{ijk}}+\mathrm{e}_{\mathrm{ijk}}$, where $\mathbf{Z}_{\mathrm{ik}}$ only varies by region $\mathrm{i}$ and the hotel owner $\mathrm{k}$ and the $\mathbf{X}_{\mathrm{ijk}}$ vary by zip code $\mathrm{j}$ as well.

However, due to the errors $\mathrm{e}_{\mathrm{ijk}}$ in the calculation of $\mathrm{V}_{\mathrm{ijk}}$ the utility becomes random. Within this random utility framework, the probability of an owner choosing a particular zip code for a new hotel can be viewed as the product of a marginal and conditional probability.

The probability of $Y_{i j k}$ being 1 is equivalent to the probability of observing a new hotel opening in that zip code, which occurs when that location offers a higher utility versus all other options; or $\mathrm{P}\left(\mathrm{Y}_{\mathrm{ijk}}=1\right)=\mathrm{P}\left(\mathrm{Zip} \operatorname{Code}_{\mathrm{ij}}\right)=\mathrm{P}\left(\mathrm{V}_{\mathrm{ijk}}>\mathrm{V}_{\mathrm{mnk}}\right)$.

$\mathrm{P}\left(\right.$ Zip Code $\left._{\mathrm{ij}}\right)=\mathrm{P}\left(\right.$ Zip Code $_{\mathrm{ij}} \mid$ Region $\left._{\mathrm{i}}\right) * \mathrm{P}\left(\right.$ Region $\left._{\mathrm{i}}\right)$, where P(Zip Code $\mathrm{ij}_{\mathrm{ij}} \mid$ Region $\left._{i}\right)$ is the probability of choosing Zip Code ${ }_{j}$ conditional on the choice of Region .

If the residuals are drawn from an extreme value (Gumbel) distribution, then we can write:

$\mathrm{P}\left(\right.$ZZip Code $_{\mathrm{ij}} \mid$ Region $\left._{\mathrm{i}}\right)=\exp \left(\mathbf{b}_{2}{ }^{\prime} \mathbf{X}_{\mathrm{ij}}\right) / \exp \left(\mathrm{I}_{\mathrm{i}}\right)$ where $\mathrm{I}_{\mathrm{i}}=\log \left(\sum_{\mathrm{j}} \exp \left(\mathbf{b}_{2}{ }^{\prime} \mathbf{X}_{\mathrm{ij}}\right)\right)$, and $\mathrm{P}\left(\right.$ Region $\left._{\mathrm{i}}\right)=\exp \left(\mathbf{b}_{1}{ }^{\prime} \mathbf{Z}_{\mathrm{i}}+\mathrm{b}_{3} \mathrm{I}_{\mathrm{i}}\right) / \Sigma_{\mathrm{m}} \exp \left(\mathbf{b}_{1}{ }^{\prime} \mathbf{Z}_{\mathrm{m}}+\mathrm{b}_{3} \mathrm{I}_{\mathrm{m}}\right)$ where $\mathrm{m}=1$ to 25. 
These two equations can be estimated simultaneously via full information maximum likelihood (FIML). While a sequential method would be less data intensive, in this case the full information method is particularly important because we are trying to tease apart the relative importance of variables at two levels of agglomeration (the regional and zip code level). Sequential methods cannot evaluate both levels simultaneously.

The $\mathrm{I}_{\mathrm{i}}$ are called "inclusive values" and are a measure of the sum of the utilities for all zip codes within a region. The coefficients on the inclusive values, the variables $b_{3}$, measure the degree of correlation across error terms of alternatives. This correlation should be positive for zip codes within the same region since these zip codes' error terms should contain common unobservable influences. This positive correlation should exist for all zip codes in a region and for a random sample of zip codes in a region.

We note that a nested logit is a variation of McFadden's conditional logit model. In a conditional logit formulation, the investigator estimates how attributes of the choices themselves influence their likelihood of being chosen. In the case of a multinomial logit, the investigator estimates how attributes of the choosers influence what is chosen. For example, whether a person drives a BMW, a Volkswagen, or a Ford is both a function of the drivers' characteristics and the cars' characteristics. While the traditional multinomial logit focuses on the drivers' characteristics, the conditional logit focuses on the cars' characteristics. The conditional logit yields one coefficient per variable regardless of number of choices, while the multinomial logit yields N-1 coefficients per variable for a model with $\mathrm{N}$ choices. To continue the car example, a conditional model would yield a single coefficient for the independent variable "miles per gallon", while the variable "consumer's income" in a multinomial setting would yield one coefficient for its effect on the choice of a BMW relative to the baseline choice of a Ford, and one for the Volkswagen, again relative to the choice of a Ford. For a comprehensive presentation of the nested logit model the reader is referred to McFadden (1978), Ben- Akiva and Lerman (1985); and Maddala (1983). 


\subsection{The Data and Results}

The dependent variable is where new hotels were built - in which zip code within which region. Independent variables are characteristics of where these hotels were built versus where they were not. Using our data from the Texas State Government we include an observation for all 741 new hotels built in Texas between 1991-1998, including 59 owned by Patels. ${ }^{17}$

The independent variables of theoretical interest are the counts of existing Patel hotels in each zip code and region at the time the decision is made by owner $\mathrm{k}$ to open the new hotel. An interaction term is added that equals the count of existing Patel hotels if the owner choosing the location is a Patel and zero otherwise. We include the choices of non-Patel hoteliers to determine whether the Patels behavior is any different from that of the other hotel owners.

The other variables are included as control variables. At the zip code level, we include population and average income to reflect demand. For the nature of supply, we include the counts of chain hotels and incorporated non-chain hotels at both the zip code and regional levels. As Patels are more likely to be non-incorporated than the general population of hotel owners, the incorporated counts must be included to prevent significance from being attributed to membership in the Patel group. The inclusion of the chain variable has similar rationale, because the chain membership is negatively correlated with Patel ownership.

Results are shown as Table 2 below. Regional level variables are grouped above zip code level variables.

\section{[ Table 2 about here ]}

Before interpreting the coefficient estimates, we need to assessing the suitability of our nested structure using the coefficients attracted by the "inclusive values" - the estimate of the sum of the utilities for all zip codes within a region. The coefficients on the inclusive values measure the degree of correlation across error terms or alternatives

\footnotetext{
${ }^{17}$ While having some data for hotels founded before 1991, we do not have full information on the competitive landscape since for those hotels established before 1991, the data set only includes surviving hotels. We only observe survivors. Therefore, we limit our panel to 1991 and after.
} 
and therefore should range from zero to one. But a large number of inclusive values greater than one indicates that the alternatives in different nests are actually more correlated than those within the given nest, implying that the analyst has not chosen a valid nesting structure. To determine our nesting structure, we initially group zip codes into regions based upon contiguity, common access to the same interstate highway, and proximity to potential regional centers. With our 25 regions, 24 of the inclusive values are in the range from zero to one. The one remaining is negative, but statistically not different from zero. Further, in our model, 15 of the values are statistically different from one at a $5 \%$ level or better, implying that the nesting structure is preferable to a simple single-level choice model at the zip code level. This indicates that our model is correctly specified; that is, we have chosen an appropriate nesting structure.

In Table 2, looking at the group of regional variables on the top half of the table, we see that Patels do agglomerate at the regional level, based on the positive and significant coefficient of the interaction of Patel count for Patels. In other words, Patels are more likely to choose regions of Texas that have more existing Patel hotels. Turning to the zip code level variables on the bottom half of the table, we see that this trend does not persist at this more refined geographic level. The likelihood of Patels locating in zip codes that already contain Patels does not increased or decreased in a statistically significant way. Thus, Patels agglomerate at a regional but not a zip code level.

Several control variables attract statistically significant coefficients. The coefficients for "interaction of chain count for chain" indicate that while not co-locating on a regional level, chain hotels do co-locate with other chain units at the finer zip-code level. While suggestive of chains distinctly seeking each other out, these estimates might also reflect chains being attracted by similar unobserved location traits. Interestingly, the count of incorporated non-chain variable at the zip code attracts a significant positive coefficient indicating that hoteliers are more likely to choose zip codes with non-chain hotels. Hoteliers may see such hotels as weaker competition and be drawn to such locations.

\section{Conclusion}

Recent research highlights the importance of informal links for firms' performance. We extend the inquiry into the importance of informal links by examining 
whether social and ethnic group membership alters a firm's financial performance. Group membership and informal relationships provide possible channels for members to coordinate their actions and mechanisms to discipline members who deviate from the coordinated activity. Using the rural hotel industry of Texas, we focus on hotel owners with the surname of "Patel". These Patel owned hotels compose $15 \%$ of rural hotels in Texas and anecdotal evidence suggests that Patels have extensive informal contact and cooperate with each other in the management of their hotels.

We investigated two propositions. First, whether Patel owned hotels experience enhanced financial performance when surrounded by other units also owned by Patels. Second, whether Patels tend to collocate their hotels. Our results indicate that the proximity of other Patels confers no financial performance gains; two-way fixed-effect regressions show that the prices and revenues per rooms of Patel owned hotels are not significantly different when other Patels are located close by.

To better understand this non-significant finding for financial performance, we investigate location choices by Patel owned hotels. The Patel hotels may geographically locate in such a way that makes colluding on price difficult. Using a nested logit model, we find that Patels do cluster in broad geographical areas in Texas, but not at a finer geographic level; they collocate on a regional level, but not at a zip code level. This provides a likely explanation for why the performance results showed no effect on price or revenue per room at the zip code level. They locate close enough to obtain social and cultural benefits, but not close enough for coordination on pricing. Potentially, we never observe great enough concentration of Patels at a zip code level for them to coordinate and achieve enhanced financial performance. Indeed, this suggests coordination of another type - recognizing that price maintenance with each other might be difficult, they purposefully locate far enough apart not to have to compete on price. Another potential explanation is that since the Patels fill a low-price niche, even when coordination among themselves would otherwise be possible, they are unable to charge higher prices.

Because of the lack of significance for Patel owned hotels on price or revenue performance at a local level, we do not explore whether Patels are able to behave as a single multimarket owner when dealing with other firms. Without any apparent ability to 
collude on price among themselves, it is very unlikely that they could act as a single owner in achieving mutual forbearance with competitors.

The non-significant findings for price and revenue performance do not preclude the importance of informal links. Cooperation of the Patels likely cannot be captured by price and revenue performance alone. Most of the anecdotal evidence of cooperation discussed cost-saving activities, not price heightening issues. Cooperation among the Patels in the sphere of obtaining financing, buying in bulk, or sharing information would most likely reduce costs and increase the probability of survival. If cost structures of the hotels were available, this presents a fruitful avenue for future research.

Overall, this study helps define the limits of informal links. Ingram and Roberts note that one of the main discipline mechanisms among luxury hotels is referrals overbooking by luxury hotels is common and when hoteliers are friends they will reciprocally refer surplus customers to each other. Not being considered for such referrals is a significant punishment. Such pecuniary punishment may be unavailable among Patel owned hotels, which decreases the likelihood of coordination. Future research might distinguish between direct family members and just owners with the same surname. Versus ethnic group membership, membership in the same nuclear family likely provides much stronger coordination and discipline mechanisms. Finally, since this study provides an interesting set of findings and non-findings for members of informal groups, this suggests further investigation of who agglomerates and how location choice affects performance for other groups such as chain versus non-chain hotels, single owner versus multi-unit owner hotels, and in-state versus out-of-state owned hotels. 


\section{References}

Aldrich, Howard E. and Roger Waldinger (1990) "Ethnicity and Entrepreneurship," Annual Review of Sociology, 16: 111-135.

Baum, Joel and Heather Haveman (1997), "Love thy neighbor? Differentiation and agglomeration in the Manhattan Hotel industry, 1898-1990" Administrative Science Quarterly, 42(2): 304-339.

Ben-Akiva, Moshe and Steven R. Lerman(1985), Discrete Choice Analysis, MIT Press; Cambridge, MA.

Bernheim, B. Douglas and Michael D. Whinston (1990), "Multimarket Contact and Collusive Behavior," Rand Journal of Economics, 21(1): 1-27.

Chung, Wilbur and Arturs Kalnins (2000), "Localized Agglomeration Spillovers and Firm Performance: A Test of the Texas Lodging Industry," unpublished working paper - Stern School of Business, New York University.

Conlin, Mike (1999), “An empirical analysis of the effect of divisionalization and franchising on competition" unpublished working paper - Department of Economics, Cornell University.

Dixit, Avinash (1980), “The Role of Investment in Entry Deterrence," Economic Journal, 90 (March), 95-106.

Ellickson, Robert (1989), "A Hypothesis of Wealth-Maximizing Norms: Evidence from the Whaling Industry," Journal of Law, Economics and Organization, 5:83-97.

Evans, W. N., and Kessides, I. N. (1994), "Living by the "golden rule": Multimarket contact in the U.S. airline industry". Quarterly Journal of Economics, 109: 341-366

Fudenberg, Drew and Jean Tirole (1991), Game Theory. MIT Press, Cambridge, MA.

Gimeno, Javier (1999), "Reciprocal Threats in Multimarket Rivalry: Staking Out Spheres of Influence in the U.S. Airline Industry," Strategic Management Journal, 20: 101-128.

Granovetter, Mark (1995) “The Economic Sociology of Firms and Entrepreneurs,” in Alejandro Portes, ed., The Economic Sociology of Immigration: Essays on Networks, Ethnicity, and Entrepreneurship, , Russell Sage Foundation, New York, NY.

Greve, Henrich R (1995), "Jumping ship: The diffusion of strategy abandonment," Administrative Science Quarterly, 40 (3): 444-474.

Hadfield, Gillian (1991), "Credible Spatial Pre-emption Through Franchising," Rand Journal of Economics, 22 (4), 531-543. 
Ingram, Paul and Peter W. Roberts (2000), "Friendship among competitors in the Sydney hotel industry" American Journal of Sociology, forthcoming.

Judd, Kenneth L. (1985), “Credible Spatial Preemption,” Rand Journal of Economics, 16 (Summer): 153-166.

Levy, David T. and James Reitzes (1992), “Anticompetitive Effects of Mergers in Markets with Localized Competition," Journal of Law, Economics and Organization, 8: 427-440.

Maddala, G. S. (1983), Limited Dependent and Qualitative Variables in Econometrics. Cambridge: Cambridge University Press.

McFadden, Daniel (1978), "Modeling the choice of residential location," in P. Karlqvist et al. , eds., Spatial Interaction Theory and Planning Models, North Holland: Amsterdam.

Millman, Joel (1997), The Other Americans: How Immigrants Renew Our Country, Our Economy, and Our Values, New York: Viking.

Redding, S. Gordon (1996), "Weak Organizaqtions and Strong Linkages: Managerial Ideology and Chinese Family Business Networks," in Gary G. Hamilton, ed., Asian Business Networks, Berlin: DeGruyter.

Uzzi, Brian (1996), "The sources and consequences of embeddedness for the economic performance of organizations: The network effect," American Sociological Review, 61: 674-698.

Werden, Gregory J. and Luke Froeb (1994), “The Effects of Mergers in Differentiated Products Industries: Logit Demand and Merger Policy," Journal of Law, Economics and Organization, 10: 407-422.

Williamson, Oliver (1993), “Calculativeness, trust, and economic organization,” Journal of Law and Economics, 34:453-502

Williamson, Oliver (1996), "Economic Organization: The Case for Candor," The Academy of Management Review, 21:48-57.

Wong, Siu-lin (1988), Emigrant Entrepreneurs: Shanghai Industrialists in Hong Kong, Hong Kong:Oxford University Press. 


\section{Table 1: Determinants of Hotel Financial Performance}

Ordinary Least Squares (OLS) with 2-way fixed effects

\begin{tabular}{|c|c|c|c|c|}
\hline & \multicolumn{2}{|c|}{$\begin{array}{l}\text { Dep. Var. is } \\
\text { Room Price }\end{array}$} & \multicolumn{2}{|c|}{$\begin{array}{c}\text { Dep. Var. is } \\
\text { Revenue/Room }\end{array}$} \\
\hline & Coefficient & Std. Error & Coefficient & Std. Error \\
\hline Patel-owned hotel & 0.168 & 2.005 & -0.021 & 0.111 \\
\hline $\begin{array}{l}\text { Pct Patel hotels in zip } \\
\text { code }\end{array}$ & 4.227 & 4.342 & -0.085 & 0.239 \\
\hline $\begin{array}{l}\text { Interaction of Patel- } \\
\text { owned and pct Patel }\end{array}$ & -2.795 & 8.274 & -0.598 & 0.456 \\
\hline $\begin{array}{l}\text { Multimarket contact, } \\
\text { owner level }\end{array}$ & $0.255^{* *}$ & 0.052 & $0.017 * *$ & 0.003 \\
\hline $\begin{array}{l}\text { Multimarket contact, } \\
\text { chain level }\end{array}$ & -0.068 & 0.053 & -0.005 & 0.003 \\
\hline Incorporated hotel & $3.771^{* *}$ & 1.348 & $0.377^{* *}$ & 0.074 \\
\hline Room count in hotel & $0.154^{* *}$ & 0.013 & $0.002 *$ & 0.001 \\
\hline AAA stars (if listed) & $1.590^{* *}$ & 0.572 & $0.150^{* *}$ & 0.032 \\
\hline 1990 Zip population & $-0.276^{* *}$ & 0.056 & 0.002 & 0.003 \\
\hline 1990 Average income & $0.330^{*}$ & 0.142 & 0.011 & 0.008 \\
\hline Hotels in zip code & $0.854 * *$ & 0.132 & 0.003 & 0.007 \\
\hline Interstate in zip code & $-7.193 * *$ & 2.072 & $-0.228 *$ & 0.114 \\
\hline Herfindahl index & $5.039 *$ & 2.093 & 0.145 & 0.115 \\
\hline Chain \& county dummies & Yes** $^{* *}$ & & Yes** & \\
\hline $\mathrm{R}^{2}$ & 0.691 & & 0.648 & \\
\hline $\mathrm{N}$ & 1097 & & 1097 & \\
\hline
\end{tabular}




\section{Table 2: Determinants of Hotel Location Choice}

Full information maximum likelihood (FIML) Nested Logit

\begin{tabular}{|c|c|c|}
\hline & \multicolumn{2}{|c|}{$\begin{array}{c}\text { Dep. Var. is } \\
\text { Choice of Zip Code }\end{array}$} \\
\hline & Coefficient & Std. Error \\
\hline \multicolumn{3}{|l|}{ Regional level variables $\left(b_{3}\right)$} \\
\hline Count of hotels owned by chooser & $0.734 * *$ & 0.118 \\
\hline Count of chain hotels & $-0.068 * *$ & 0.021 \\
\hline Count of Patel-owned hotels & -0.033 & 0.050 \\
\hline Count of incorporated non-chain hotels & 0.032 & 0.025 \\
\hline Interaction of chain count for chain & 0.008 & 0.015 \\
\hline Interaction of Patel count for Patels & $0.174 *$ & 0.073 \\
\hline \multicolumn{3}{|l|}{ Zip code level variables $\left(\mathbf{b}_{2}\right)$} \\
\hline Population of zip code (1990) & 0.006 & 0.004 \\
\hline Avg Income of zip code (1990) & $0.014 *$ & 0.006 \\
\hline Count of chain hotels & -0.001 & 0.052 \\
\hline Count of Patel-owned hotels & -0.107 & 0.127 \\
\hline Count of incorporated non-chain hotels & $0.250 * *$ & 0.067 \\
\hline Interaction of chain count for chain & $0.472 * *$ & 0.082 \\
\hline Interaction of Patel count for Patels & 0.181 & 0.354 \\
\hline $\begin{array}{l}\text { Inclusive values } \\
\text { Log Likelihood }\end{array}$ & $\begin{array}{l}\text { Yes** } \\
-3033 * *\end{array}$ & \\
\hline
\end{tabular}

$* *: \mathrm{p}<0.01 ; *: \mathrm{p}<0.05$ 